\title{
Creative migration: A Western Australian case study of
}

\section{creative artists}

ABSTRACT It is well known that a pilgrimage overseas can be crucial to the career development of specialist creative artists. All too often, however, the pilgrimage becomes a permanent migration. Significantly, the loss of this creative talent is not limited to the national level. The dominance of cities as the centres of Australia's knowledge-based economy leads also to migration of creative artists from regional centres and from smaller cities such as Perth, lessening the potential for those regions to attract and retain creative and innovative people. Given the globalised nature of the cultural industries and the emergence of new technologies, this study of Western Australian creative artists whether migration loss could be repositioned as cultural gain. Initial results suggest that spatial separation due to geographic isolation is particularly problematic for Western Australian creative artists both within the regions and the metropolitan area. Despite participants' strong personal connections with Western Australia, artistic connections were tenuous and artistic involvement was negligible. Implications include the need to actively engage with creative migrants by fostering their continued involvement in the cultural life of cities and regions.

KEY WORDS Creative workforce; migration; artists; creative cities; creative capital 


\section{Introduction}

Creativity, whether that of artists or of those whose creativity is embedded within other areas of the economy, is often cited as crucially important to the economy (Anheier \& Isar 2008; Glaeser 2003). However, many such claims derive from place-competition strategies such as Florida's theory of a creative class (2002), which somewhat simplistically positions creative artists as magnets for creating "cool city" images (Peck 2005) to generate in-migration of creative and talented thinkers.

Since the creative industries discourse began with Keating's 1994 Creative Nation policy statement (Commonwealth of Australia 1994), the arts have received increasing attention within discussions of human capital, regeneration, community engagement, branding and image (Markusen \& Gadwa 2009; Pratt 2009; Vanolo 2008). These alignments have fuelled a plethora of reports on the societal and economic roles played by the arts; however, little of this research documents the practice, migration and working lives of individual creative artists. The deficiency relates partly to the sheer variety of scale, economic activity and organisation of the creative industries, which Hartley (2005, p. 26) describes as 'an entirely new species of cultural and economic enterprise ... whose shape and extent has yet to be properly mapped and understood, even by the people involved'. The complexity of artists' work is such that it is not captured by national data collections that fail to take into account multiple employments. Indeed, Throsby suggests that Australian census data underestimate the artist population by over 50 percent (Throsby 2008a; Throsby \& Hollister 2003), and Pratt (1997, p. 2) agrees that intensive analysis of the sector can be achieved only through empirical research, given that 'original data sources are weak and inadequate for the purpose'. 
There is, similarly, little research on the migration of creative artists (Houston et al, 2008). The complexities of creative labour research are compounded in this respect because artist migration can be temporary, and temporary migration is generally an under-researched area yet to be sufficiently recognised by either researchers or demographic and labour data collection agencies' (Hugo 2006, p. 212).

Careers featuring multiple employments and limited opportunities within complex markets remain significant influences among the artist population, and a pilgrimage overseas remains a logical feature of career development. Many present-day creative artists will travel in order to develop their careers, reach larger markets, and work within established industries elsewhere in the world: 'the nomadism of artists is naturally a concerted action of moving and settling in order to discover and to create, in order to renew one's awareness and one's formal responses' (Haerdter 2005, p. 7). This migration is largely accepted by the creative sector, especially when the move is the result of a significant career opportunity.

Whilst artistic success is celebrated, however, the physical loss of creative artists and their work is often lamented by artists' places of origin, especially when the travel becomes permanent or long-term migration. Just as creative artists migrate overseas, the dominance of cities as the centres of Australia's knowledge- or experience-based economy leads to migration from regional centres and from smaller and more isolated cities such as Perth. If creativity is believed to be central to economic vibrancy, this outmigration lessens the potential for these areas to retain creative capital and sustain economic growth.

Given the globalised nature of the cultural industries and the emergence of new technologies, this study sought to understand some of the factors influencing artist migration and asked in what ways migration loss could be repositioned as cultural gain. 


\section{Approach}

This paper reports results from a study of specialist creative artists practising within the "core" creative industries (Throsby 2008b) of music, visual arts and film. Specifically, the study provided a snapshot of Western Australia's creative diaspora: creative artists living and working overseas or in the Eastern states of Australia. Participants, cited here using pseudonyms, included instrumental and vocal musicians, a conductor, a producer, a composer and a visual artist (five females and three males). Although this was a small sample, the depth and consistency of responses led to a wealth of information.

To avoid sample bias, participants were recruited from multiple independent sources including professional networks, alumni listings and industry press. Participants used email to answer the research questions and clarify responses. Inductive coding was employed in the analysis, and an observer independently coded responses to ensure consistency and avoid bias. Respondents were invited to answer any or all of the following four questions:

1. Do you still feel a connection with Western Australia? If so, in what ways?

2. How did leaving WA impact your career?

3. Are you likely to return to live or to visit in the future?

4. What could be done to support WA's creative people and the cultural environment?

The study was informed by the results of research involving 143 classical instrumental musicians (Bennett 2008a), which utilised a survey to gather information on career trajectories, education, location, and working patterns. Relevant findings from this formative study, taken from the responses of musicians who had migrated during the course of their careers, are incorporated into the following summary and discussion. The discussion section also draws preliminary results from a current study of the career 
ambitions of music and dance students. The discussion is structured according to the three emergent themes of cultural image, creative migration and artistic connectivity.

\section{Results and discussion}

\section{Cultural image}

It is believed that the potential for a place to attract and retain creative and talented thinkers is impacted by the richness, vibrancy and diversity of its cultural environment. Not only is creativity linked to economic success, it is a 'fundamental means through which places are perceived' (Gibson, Murphy and Freestone 2002, p. 174). Elise, a WA composer and singer now living in Berlin, noted 'incredible talent in Perth', which Melbourne-based visual artist Theo attributed to the 'unique upbringing that the unique setting of Perth allows'. However, positive comments about WA lifestyle that is 'the envy of most' (Theo) were counter-balanced by perceptions of a poor cultural image.

Despite Perth's consistently high scores in international liveability surveys, the image of Perth as "Dullsville" is perpetuated within local media. This was taken up most avidly by Theo, who wrote:

The cultural image of Perth to the rest of Australia is of a kitsch frontier town with little sophistication. This image is hard to transcend. The "West Australian", "Burkie", "WA Inc.", "Ben Cousins", "Worst of Perth" etc. is a source of much amusement. Therefore this image needs to be addressed. ... young visual artists feel the need to leave Western Australia as the cities of Melbourne, Sydney and increasingly Brisbane seem to be the centres of cultural activities and venues.

The creative migrants were asked whether they still felt a connection to WA. This was a deliberately broad question designed to elicit responses about both personal and 
professional connectedness. All of the participants expressed a strong personal connection with WA, typified by jazz performer Mia, now base in Sydney: 'Still feel like the laid back, sand-under-my feet, sun-on-my-shoulders West Australian gal. Wish I could live it and sustain my passion at the same time'.

Whilst the WA lifestyle was reported positively, a consistent theme was the different modes of practice required to sustain an arts practice in a smaller centre. Migrating back to WA despite feeling that there are 'more orchestras and performance opportunities in one corner of Hamburg than in the whole of Western Australia', one participant from the musician study (Gail) described the necessity to become selfemployed: 'I chose to come back to Australia and I discovered within a very short time that I wasn't going to have enough performing to keep myself happy, so I knew I was going to have to create it. So I did.' The presence of an established music industry in WA made it possible for Gail to adapt her practice. For other artists, such as the TV producer discussed later, the lack of a local industry makes it impossible to return: she 'couldn't move to Perth, a city without a sitcom, without changing careers'.

The perceived vibrancy of a place, or what Jess and Massey (1995) term a "mental sense of place", is influenced by the visibility of its activities. Despite Perth's reputation for a unique popular music scene (Stratton 2008), the city centre does not have the cultural heart or hub of many other cities; hence many cultural activities can be invisible to the uninformed. A study conducted for the Department of Culture and the Arts (DCA 2008) concluded that locating a list of WA and even Perth-based events was impossible without prior knowledge of where to look. The study recommended the formation of a website hosted by, or with a direct link from, Tourism WA (Bennett 2008b). A simultaneous survey conducted by the City of Perth found that image and vibrancy are also a concern for local residents. The survey attracted 600 responses and 
identified fifteen major issues, three of which have particular relevance to the visibility of cultural activities:

- Development, attraction and support of creative and cultural activities;

- The need to enhance entertainment, dining and retail activities to increase the vibrancy and liveability of the city; [and]

- The need to focus on all aspects of the visitor experience to create a real 'buzz' for both interstate and overseas visitors. (City of Perth 2009, n. p)

An initiative to arise directly from the City of Perth study is the proposed "What's on in Perth" website. Although the website will initially profile only events within the City, it promises to be an important initial step towards bringing together Perth-based and regional events into a searchable database for residents and visitors.

\section{Creative migration}

Real-time or performative arts practice has distinct implications for mobility because of the physicality and transience of the practice. The study drew on data from the musician research to ascertain the commonality of artist migration within a larger group of realtime creative artists. The 143 musicians were found to have studied in 208 locations including the United States, Europe, the Middle East and Australia. Of the 105 respondents based in WA, 38 percent were migrants and a further 29 percent had migrated for work and study. The music study found a similarly high proportion of international artists within orchestras: 30 percent of orchestral participants had migrated from other countries and a further 27 percent had lived or studied elsewhere. Results are consistent with Jang's (1996) findings that approximately one third of Korea's orchestra members come from outside of Korea. 
For WA creative artists, who are closer to South East Asia than to Sydney and Melbourne, the difficulties of maintaining a sustainable creative practice is exacerbated by the wide spatial distribution of arts activity that deems intrastate, interstate and international touring prohibitively expensive. There is almost twice the rate of cultural industries occupation in Perth as there is in the balance of the state and WA has the highest metropolitan primacy in Australia (Gibson, Murphy \& Freestone 2002). The vast distances between major centres presents a challenge for both independent and employed artists, such as orchestral musicians for whom changing orchestra necessitates moving state. None of the orchestral musicians in the musician study expected to remain with their orchestras, and many expected to leave behind family and friends in order to progress their careers. However, migration interstate or overseas becomes increasingly problematic as family and social ties are developed. Some of the musicians suggested that these barriers had become overwhelming: orchestral musician Deborah described the pressures of travel as being 'incompatible with growing family commitments', whilst drummer Matt found that 'the economic realities of sustaining a family did not agree with a life on the road or raising children in the comfort they deserve to experience'. Shifting priorities arose as an important factor:

When once I was yearning for the illusive celebrity status so common to many teenagers, my ego seems to have finally receded to the point that I can now see who I truly am. I love performing, but the quest is no longer associated with fame. (WA-based pianist, Beth)

It is likely that similar factors exist across the arts, which raises the question of how much artist migration is reactive and how much pre-meditated. The extent to which future artists intend to travel or migrate is being investigated in a study of career hopes and expectations. The study has so far surveyed 186 first year undergraduate music and 
dance students in WA, asking the students to consider their careers up to five years after graduation. Initial results present a startling picture. A random sample of 40 surveys reveals that 83 percent intend to work in the Eastern States or overseas. Thirty-five percent of the students plan a permanent migration.

Although this is merely an indication of career ambition, the results align with the level of migration reported within the music study and strongly suggest that migration is commonly planned prior to the commencement of professional practice. Drawing on a "global imagination" (Rizvi 2000), a key driver for artists is the desire to make a mark within the imagined buzz of larger or exotic markets, increasing their status through national or international activity. Heightened status is illustrated in research conducted by Gibson (2003, p. 210), who noted that visiting artists can earn more because of their outside identity: 'mileage was made out of the credible or exotic nature of those [musical] products sourced from other locations'.

Whilst migration can be pre-meditated, the research also found much artist migration to be a reactive, reluctant move. The primary driver for artists was, in fact, a lack of local opportunities:

I made some attempts to find employment with Western Australian film and television companies but quickly found that there were very few opportunities. ... When I moved to Los Angeles I had hundreds more job options available to me. (Greta, TV producer living in California)

David, a professional trombonist, reflected:

By moving to Melbourne I was exposed to a greater population of musicians, venues and audiences, therefore my performance opportunities increased. Being geographically closer to other cities also opens up more performance opportunities. 
Carla, now a lead opera singer, gained continuous employment once she migrated to Germany:

The year I auditioned at WA Opera there was only one position in the opera chorus going, and ten times that amount were applying for it - just to sing in the chorus [positions contracted on a seasonal basis].

Writing from Berlin, composer and jazz singer Elise made the connection between opportunities and venues: 'I'm sure I will visit Perth again but it is difficult to live there because of its limited venues and opportunities to play live'. Berlin is a particularly good example of a city that has embraced creative industry activities since the Cold War era, utilising derelict buildings to establish studio spaces and a vibrant cultural sector: ‘Berlin's government and its people have taken a bet on creativity by plugging the gap in the economy as the city is rebuilt, and it is paying off' (Heath 2009, p. 140).

Dellbrügge and de Moll (2005) interviewed thirty artists in an attempt to identify a topology of attitudes and behavioural patterns among artists who had migrated to Berlin. They found that 'there is a necessity-even in Berlin-for most visual artists to earn money with odd jobs to finance their career' (p. 140). Further, 'artists may not necessarily benefit, as content-providers and generators of the creative setting, from the successful city branding through culture' (p. 142). Nonetheless, the Berlin artists cited pull factors including low cost of living, increased status due to their Berlin identity and, crucially, opportunities for critical debate among both artists and the general population. The presence of so many artists enabled them to feel that their work and working patterns were normal: 'frees them of the pressure to play the role of exotic creatures' (p. 141). Similarly, Drake, in his study of UK artists, found that 'locality-based intensive social and cultural activity may be a key source of inspiration' (2003, p. 522). 
Drake's respondents referred to 'the "buzz", unpredictability or excitement' (ibid) of a specific city location in much the same way that the WA students imagined Eastern States and overseas locations, and the artist sample had imagined major centres such as Berlin and Melbourne.

Artists in many smaller centres require a 'fluidity of creative identities' (Luckman et al. 2008, p. 628) to sustain their arts practice. Even with multiple identities, the availability of local opportunities can be critical: as trombonist David explained, many WA artists 'have to work other jobs to fund the time for their passion; however in large cities many artists can work full time'. Melbourne-based pianist Jenny observed that 'the population of Perth and lack of proximity to fairly large regional towns and centres' can render full-time arts practice impossible and can confine artistic practice to what Theo described as 'a fringe activity'. This is exacerbated in WA by the high cost of travel, which often means that the cost of a regional tour far exceeds that of an interstate tour that could reach much larger markets. Viability is also threatened by the demise of venues, the result of multiple factors including the gentrification of inner city areas including key entertainment districts (Johnson \& Homan 2003). With most artists working across multiple genres, sectors and in various situations (Markusen et al. 2006), venue demise has been felt across the visual and performing arts. Ironically, in this era of increasing artist independence, exposure via performances and exhibitions is vital to maintaining market share, being visible and remaining connected.

\section{Artistic connectivity}

Despite a desire among study participants to be involved in WA arts activities, artistic connections were tenuous and artistic involvement was negligible. Jazz performer Mia 
had attempted to remain involved: 'I used to try to organise gigs but it became too difficult for effort versus return'. Perth, she wrote, needs

... more public venues/community events that support non-mainstream style entertainment, government support for innovative projects. Promotion of West Australian artists to greater Australia and the world. I've always felt some sort of national 'gig circuit' or 'exchange' performance set up would stimulate performers and audience alike. Some sort of public creative 'hub' like you might find at somewhere like Federation Square in Melbourne ... where general public are regular exposed to music, art, acts they might not normally get to see/hear.

Jenny (pianist) had tried to organise Perth concerts from Melbourne in order to remain involved in the WA arts scene. However, she had found that:

... often it feels like that if one wants to stage anything, it has to be individually organised, managed and put on, without support. ... The difficulty in finding appropriate and prestigious venues lessens the incentive for artists to showcase their talents, particularly as most of the prestigious venues with good facilities usually put on concerts under larger banners.

Similarly, Gavin, a big band leader now living in Norway, wrote of Western Australia's 'extremely high level of musicianship', but he conceded: 'I won't be living there again. As much as I would like to, there are too many limitations'.

Two respondents believed that their migration had resulted in them being less than welcome within the "local" arts scene. For example, Berlin-based singer Carla, wrote:

I feel connected to the WA music scene, but I wish I was more connected. ... I think they [name of company] have the policy too, of supporting performers who have chosen not to leave Perth. I hope this will change in time. 
Again reflecting the need for inter- and intra-connectedness, jazz singer Elise wrote of the 'open, enthusiastic attitude' she had encountered in other cities and suggested: 'community, students, teachers, and people who just want to be involved need to stick together, especially in a small city like Perth'.

The WA cultural industries are characterised by sparse, sometimes problematic communications between multiple of networks. This fragmented communication is typical of a sector founded on grass roots community based social networks. The desire to connect artistically emerged as a significant theme among the creative diaspora and suggests that virtual artistic collaborations and networks would have artists' support and engagement. Whilst local critical mass is not something that can be quickly developed, the creative migrants highlighted the importance of connecting with national or global industry networks, and the difficulties they had faced in this regard when practicing in WA:

... the performing and creative arts industries are ones that benefit largely from 'who-you-know' syndrome ... furthermore, large touring acts do not always come to the West coast if they tour Australia. Having exposure to international artists in the Eastern States broadens and deepens one's perspective. (Jenny)

Most of the respondents alluded to the "invisibility" and professional isolation they had experienced when they had based their practice in WA: 'it is very difficult to transcend the regionalism and participate in the national conversation about visual culture' (Theo). This comment reflects the importance of critical debate, which was such a draw card for the Berlin artists. Isolation was in part aligned with the need to be aware of opportunities as they arise; and yet, as Greta wrote from California, the solutions can be quite simple: 'through my UCLA [University of California, Los Angeles] writing course ... I received a weekly email with a hundred or so entry level jobs'. 
Several participants noted that smaller centres require a greater entrepreneurial approach to creating and managing performance or exhibition opportunities. The entrepreneurial skills required to build sustainable arts careers are often absent or underdeveloped in the formative stages of artists' careers. This impacts the ability of emerging artists to creative a viable practice, particularly in smaller centres where more opportunities need to be self-generated. The impact of migration on creative artists who migrate early in their professional careers, when friends and family can be critically important, is an issue deserving of further research. Theo made the point that a smaller market can provide valuable opportunities for early career development. He reminisced:

I left as a young adult, and I was surprised at how moving to another city as a young artist was with difficulty. I had to form new social and support networks and this did take years to form. Ironically, I feel that I missed out on opportunities that colleagues in Perth were allowed, in particular grants and commissions. Therefore my early development through opportunities as an artist may have been stunted.

One of the obvious strategies for retaining and engaging emerging artists is to connect them with their professional fields whilst they are still training. Although this occurs frequently within some of the visual arts and within contemporary music, in other fields it is common for new graduates have little or no professional connections, as was the experience of TV producer Greta:

When I graduated I wasn't given any instruction on how to use my film studies in Western Australia. In three years of university I hadn't met anyone who was actually working in production or post-production in Perth. I didn't study Western Australian films, attend any local film festivals or learn anything about making 
films or television in small creative communities like WA. Essentially I knew nothing about the workings of the Perth entertainment industry and, as a result, quickly decided to move to away from the State.

Pianist Jenny noted the initiative of Melbourne radio station $3 \mathrm{MBS}$, which supports a resident artist program and weekly lunchtime classical music concerts at which young performers and performance students perform live-to-air from the studio, providing 'invaluable experience, something to work for and, as far as I can see, is mutually beneficial to all involved'. Relatively simple initiatives, such as shared bulletins, live-toair concerts and exhibition or performance spaces within city buildings and public spaces, produce both opportunities and vibrancy. They also contribute much-needed venues.

\section{Concluding comments}

The migration of creative artists is driven by push factors (Lee 1966) such as limited local opportunities and geographic isolation, and pull factors including experience, identity, networks, and the draw of more established industries or geographic clusters of activity.

Despite some alignment, it is clear that research on artist migration, including the spatial distribution of artists within metropolitan areas, is not generalisable from the results of research on the creative class. Nor do existing primary data provide a reliable base for such research. Recent research from Sweden (Hansen and Niedomysl 2009) suggests that migration among the creative class (used as a proxy for human capital) is driven primarily by employment, closely followed by friends and family. Creative artists similarly migrate for employment; however the move is rarely the result of securing a position. Rather, it tends to be a move to a location where there are increased opportunities to create work, 
either because of the presence of an established industry, or simply because of a larger population base. This is often an unstable migration involving financial risk. Another important difference is that whereas the creative class was drawn towards friends and family, artists tend to move away from important social networks in order to further their artistic practice. In a sector where increased success often equates to increased time away from home, artists moving towards friends and family often do so at the expense of their practice.

Given that artists can be creatively generative in terms of the way in which a place is imagined, their involvement in both the process and project of globalisation is a largely unrealised asset little celebrated within the local context. Using the examples of the Australian-derived Village Roadshow and Hopscotch Films, O’Neil (2009) observes that the 'commercial success of Australian companies in the creative economy is scarcely acknowledged here' (p. 32); and yet the success of such creative endeavours could form an important component of how their place of origin is imagined.

Perhaps this is an element of migration and identity that has shifted in recent times. In 1983, Anderson suggested that communities 'are to be distinguished not by their falsity/genuineness, but by the style in which they are imagined' (p. 6). However, this idea has less credence in the context of societies imagined from a global perspective: in fact, the project and process of globalisation may now reinforce that which is locally believed and thought about (Moore and Held 2007). Whilst globalisation and advanced technologies can be imagined as threats to local cultures and community identities, they also offer new opportunities to retain long-term, tangible links between creative artists and their places of origin. Virtual networks are invaluable in fostering much-needed and valued critical debate, and much could be done to connect local artists with national and international networks including those involving creative migrants. This would also enhance the value of experience brought back to the local context. 
The study provides a snapshot of the drivers influencing artist migration, and the findings strongly suggest the need to actively engage with creative migrants, fostering their continued involvement as active agents in the cultural life and image of our cities and regions. A targeted program of virtual collaborations could go a long way towards connecting artists and community regardless of artists' locations, repositioning creative migration as a positive element of local identities. It is hoped that further empirical research into the geography of artistic talent will shed more light on this fascinating area of research.

\section{References}

ANDERSON, B. (1983) Imagined communities: reflections on the origins and spread of nationalism, Verso, London.

ANHEIER, H., \& ISAR, R. (eds) (2008) Cultures and globalization: the cultural economy, Sage, London.

BENNETT, D. (2008a) Understanding the classical music profession: the past, the present and strategies for the future, Aldershot, Ashgate Publishing Limited.

BENNETT, D. (2008b) Somewhere to play: venues and live original music in Western Australia, Perth, Department of Culture and the Arts.

BRITISH COUNCIL (1999) Creative industries export, London, British Council.

BROWN, R. (2007) 'Enhancing student employability? Current practice and student experiences in HE performing arts', Arts and Humanities in Higher Education 6(28), pp. 28-48.

CITY OF PERTH (2009) City of Perth 2029: we hear you! Perth, City of Perth. COMMONWEALTH OF AUSTRALIA (1994) Creative nation: Commonwealth cultural policy, Canberra, Department of Communications and the Arts. 
DELLBRÜGGE, C., \& DE MOLL, R. (2005) Artist migration Berlin, Heidelberger Kunstverein, Berlin.

DEPARTMENT OF CULTURE AND THE ARTS (DCA) (2008) Arts and culture in Western Australia, Perth, DCA.

DRAKE, G. (2003) “"This place gives me space”: place and creativity in the creative industries', Geoforum 34, pp. 511-524.

FLORIDA, R. (2002) The rise of the creative class, Basic Books, New York.

GIBSON, C., MURPHY, P., \& FREESTONE, R. (2002) 'Employment and socio-spatial relations in Australia's cultural economy', Australian Geographer 33(2), pp. 173-189. GIBSON, C. (2003) 'Cultures at work: why "culture” matters in research on the "cultural” industries', Social and Cultural Geography 4(2), pp. 201-215.

GLAESER, E. (2003) 'The new economics of urban and regional growth', in Clark, G., Feldman, M., \& Gertler, M. (eds) The Oxford handbook of economic geography, Oxford, Oxford University Press, pp. 83-98.

HAERDTER, M. (2005) NeMe: remarks on modernity, mobility, nomadism and the arts. Presentation given at Res Artis, Cyprus, April. Available at: http: neme.org/main/137/nomadism (accessed 25 May 2009).

HANSEN, H., \& NIEDOMYSL, T. (2009) 'Migration of the creative class: evidence from Sweden', Journal of Economic Geography 9(2009), pp. 191-206.

HARTLEY, J. (2005) 'Creative industries', in Hartley, J. (ed) Creative industries, Massachusetts, Blackwell Publishing, pp. 1-40.

HEATH, R. (2009) 'Risky business in challenging times', in Schultz, J. (ed) Essentially creative, Griffith Review Autumn 2009, Sydney, ABC Books, pp. 137-146. 
HOUSTON, D., FINDLAY, A., HARRISON, R., \& MASON, C. (2008) ‘Will attracting a "creative class" boost economic growth in old industrial regions? A case study of Scotland', Geografiska Annaler B(90), pp. 133-149.

HUGO, G. (2006) 'Temporary migration and the labour market in Australia', Australian Geographer 37(2), pp. 211-231.

JANG, K. (1996) 'Dear friends! Let us start over', in Oliva, G. M. (ed) The ISME Commission for the Education of the Professional Musician 1996 seminar. The musician's role: new challenges, Universitetstryckeriet, Lund, pp. 25-136.

JESS, P. \& MASSEY, D. (1995) 'The conceptualization of space', in Massey, D., \& Jess, P. (eds) A place in the world: Places, cultures and globalization, Oxford, Oxford University Press, pp. 45-85.

JOHNSON, B. \& HOMAN, S. (2003) Vanishing acts: an inquiry into the state of live popular music opportunities in New South Wales, Sydney, Australia Council and the NSW Ministry for the Arts

LEE, E. S. (1966) 'A theory of migration', Demography 3, pp. 47-57.

LUCKMAN, L., GIBSON, C., FITZPARTICK, D., BRENNAN-HORLEY, C., WILLOUGHBYSMITH, J., \& HUGHES, K. (2009) Creative tropical city: Mapping Darwin's creative industries, Charles Darwin University, Darwin.

MARKUSEN, A., GILMORE, S., JOHNSON, A., LEVI, T., \& MARTINEZ, A. (2006). Crossover: how artists build careers across commercial, nonprofit and community work. Project on Regional and Industrial Economics, Humphrey Institute of Public Affairs, Minneapolis, University of Minnesota.

MARKUSEN, A., \& GADWA, A. (2009) Arts and culture in urban/regional planning: a review and research agenda. Working paper \#271. Project on regional and industrial economics, Minneapolis, University of Minnesota. 
MAZANTI, B. (2007) ‘Choosing residence, community and neighbours-theorizing families' motives for moving', Geografiska Annaler 89B(1), pp. 53-68.

MOORE, H. \& HELD, D. (eds) (2007) Cultural politics in a global age, One World, Oxford.

O’NEIL, H. (2009) 'Ratbags at the gates', in Schultz, J. (ed) Essentially creative, Griffith Review Autumn 2009, Sydney, ABC Books, pp. 11-40.

PECK, J. (2005) 'Struggling with the creative class', International Journal of Urban and Regional Research 29(4), pp. 740-770.

PRATT, A. (1997) 'The cultural industries production system: a case study of employment change in Britain, 1984-91', Environment and Planning A 29(11), pp. 1953-1974.

PRATT, A. (2009). 'Urban regeneration: from the arts "feel good" factor to the cultural economy: a case study of Hoxton, London', Urban Studies 46(5-6), pp. 1041-1061.

RIZVI, F. (2000) 'International education and the production of the global imagination, in Burbules, N., \& Torres, C. (eds) Globalization and education: critical perspectives, New York, Routledge, pp. 205-227.

STRATTON, J. (2008) 'The difference of the Perth music: a scene in cultural and historical context', Continuum 22(5), pp. 613-622.

THROSBY, D. (2008a) Creative Australia: the arts and culture in Australian work and leisure, (Occasional Paper 3/2008), Canberra, The Academy of the Social Sciences in Australia.

THROSBY, D. (2008b) ‘The concentric circles model of the cultural industries’, Cultural Trends 17(3), pp. 147-164.

THROSBY, D., \& HOLLISTER, V. (2003) Don't give up your day job: an economic study of professional artists in Australia, Catalogue No. 331.7617, Sydney, Australia Council. 
VANOLO, A. (2008). 'The image of the creative city: some reflections on urban branding in Turin', Cities 25, pp. 370-382. 